Research report

\title{
Learning through school meals?
}

\author{
Jette Benn*, Monica Carlsson \\ Department of Education, Aarhus University, Tuborgvej 164, DK 2400 Copenhagen, Denmark
}

\section{A R T I C L E I N F O}

\section{Article history:}

Received 4 October 2013

Received in revised form 4 March 2014

Accepted 10 March 2014

Available online 20 March 2014

\section{Keywords:}

School meals

Content

Competencies

Learning

Participation

\begin{abstract}
A B S T R A C T
This article is based on a qualitative multiple case study aimed at evaluating the effects of free school meal interventions on pupils' learning, and on the learning environment in schools. The study was conducted at four schools, each offering free school meals for 20 weeks. At each school individual and focus group interviews were conducted with students in grades 5 to 7 and grades 8 to 9 . Furthermore, students were observed during lunch breaks, and interviews were conducted with the class teacher, headmaster and/or the person responsible for school meals. The purpose of the article is to explore the learning potentials of school meals. The cross-case analysis focuses on the involved actors' perceptions of the school meal project and the meals, including places, times and contexts, and the pupils' concepts and competences in relation to food, meals and health, as well as their involvement in the school meal project. The analysis indicates that the pupils have developed knowledge and skills related to novel foods and dishes, and that school meals can contribute to pupils' learning, whether this learning is planned or not. However, if school meals are to be further developed as an arena for learning, greater consideration must be given to the interaction between pupil, school meal and teacher than in the school meal projects presented in this study, and the potentials for learning through school meals clarified and discussed in the schools. Studying the school meal projects raises a number of dilemmas, such as whether the lunch break should be a part of or a break from education, are school meals a common (school) or private (parent) responsibility, and questions about pupils' and teachers' roles and participation in school meals.
\end{abstract}

(c) 2014 Elsevier Ltd. All rights reserved.

\section{Introduction}

In various reports, Danish Health and Medicines Authority and the government have described the health problems of children and adolescents and identified the public school system as a possible arena or setting for health interventions. In the government's health package it is stated as a goal (no. 15) that a healthy lifestyle should be supported and promoted in all settings frequented by children and adolescents (Regeringen, 2009, p. 33); furthermore it is stated that these efforts can be related to education and to learning. This article is based on a qualitative Danish case study of free school meals. The research was carried out in 2009-2011, funded by the Ministry for Foods, Agriculture and Fishery, and was one of four research studies concerning free school meal projects (Benn, Carlsson, Hesselvig Mortensen, \& Lindegaard Nordin, 2010). The EVIUS school meal projects can be seen as an example of one initiative to improve pupils' access to healthy food at school. An additional goal was to acquire a more qualified understanding of the school meal as part of learning and well-being. Schools that have not previously offered

Acknowledgements: This research was supported by the Ministry for Foods, Agriculture and Fishery of Denmark.

* Corresponding author.

E-mail address: Benn@dpu.dk ( J. Benn). school meals could apply to receive free meals for all pupils during a period of 20 weeks. Thirty-eight schools applied with 36 implementing the project. It was a requirement that local food suppliers should be used and that the meal should be related to education.

In Denmark, schoolchildren generally bring their own packed lunches from home. However, there is some historical precedence for providing free school meals. During the late nineteenth and early twentieth century, local authorities in urban areas saw it as their duty to feed needy, underprivileged children. Subsequently, school meals were regarded as a common social good for all children in those areas where they were offered. Since the 1970s, many newly built schools have incorporated tuck shops or canteens; however, these have mostly been sales outlets for a limited range of milk, bread, sandwiches and fruit. The period 1980-2000 saw several isolated school meal projects within the field of health education (Benn, 1996; Benn et al., 2010). These projects have varied in terms of objectives, with some schools using food production as a practical break in the school day, others to teach pupils how to run a tuck shop as a business, and others to develop pupils' understanding of cultural diversity and food culture. An ongoing project in a number of schools in Denmark has 'food literacy' and health as its goals (Benn et al., 2010).

The reasons for providing school meals have varied historically and geographically. For example, the English project Eat Well Do Well (Pike \& Colquhoun, 2009) uses school meals as a means of elimi- 
nating health inequalities; in Italy, school meals help pupils to learn about local food culture within a broader perspective (Morgan \& Sonnino, 2007); while in Finland (Raulio, Roos, \& Prättälä, 2010; Tikkanen \& Urho, 2009) and Sweden (Gullberg, 2006), school meals are seen as a general way of promoting healthy eating habits. In the latter case there is also focus on the 'pedagogical meal', meaning a meal which enables children and teachers to spend time together in the meal situation, but also to use the meal as both education and care, or edu-care (Persson Osowski, Göranzon, \& Fjellström, 2012, p. 15).

The article's primary purpose is to explore the learning potential of school meals. The cross-case analysis focuses on perceptions of the school meal project and the meals themselves among those involved, including the places, times and contexts of the meals, and the pupils' concepts and competences in relation to food, meals and health, as well as their involvement in the school meal project.

Following an outline of the article's primary objectives, we will now turn our attention to the methods used in the study. This will be followed by a review of the key theoretical concepts upon which the study is founded and a presentation and discussion of the findings. We conclude by drawing up a number of central dilemmas related to school meals and learning.

\section{Method and material}

The qualitative case study was planned to be carried out in four schools out of the 36 schools accepted for the free school meals purposively elected. Because of the delay of acceptance from the Ministry only 16 schools were still running the school meal project. All 16 applications for free school meals and the schools' information materials were reviewed. The final choices were grounded in geography, size of schools, and differences in food offer. The participating schools were chosen from different areas of Denmark and representing smaller and larger schools; the result was three public schools and one private school, one in a small island, two in medium sized cities, one in a larger city. All schools have both primary and lower secondary schools with classes from kindergarten class to grade 9 and two schools up to grade 10 . One of the conditions for the schools to be chosen by the Ministry for Foods, Agriculture and Fishery for free school meals were acceptance of researchers to study the effects and implications of the school meals.

The research was carried out by two trained senior researchers and two juniors from the research program of health and environmental education, working together in pairs of senior and junior. The methods chosen for the study were focus group interviews by the pair and individual interviews following a semi-structured interview guide and performed by each researcher with pupils from grades 5 to 7, classified in Denmark as the medium level age 1113 , and grades $8-9$, age $14-15$, as example of the upper level. Furthermore individual interviews were carried out with the headmaster, the person responsible for school meals and the class teacher. Both individual interviews and focus groups were scheduled 1 hour following a semi-structured interview guide. Pupils were selected by the teacher. Observations were carried out over 2 days and 3 hours in each school using observation guides, making field notes and taking photos, carried out both in the whole school setting and in the specific classes before and during the lunch break, and in the canteen or food delivery place. The pupils were asked to complete a food appraisal form to judge the food by sight, smell, texture, and taste in a scale from 1 to 6 , and opportunities to make further comments.

The observation study is a minor ethnographic study in a given school context in the everyday life of pupils as "studies of the living courses and (learning-) processes" (Borgnakke, 2004, p. 229; Burgess \& Morrison, 1998; Eisenhart, 2001). Observations or fieldwork were performed by one researcher in the different classroom settings. This work holds "the strength that everyday action, the actors' doings, but also driving conflicts and their consequences is observed and documented as "a real practice" (Borgnakke, 2004, p. 234). Interviews were conducted following semi-structured interview guidelines focusing on the school meal project's content and context, and on pupils' concepts, competencies and participation (Halkier, 2008; Kvale \& Brinkmann, 2008). The guidelines were sent to the head of the school beforehand along with information letters for parents and teachers in order to have an informed acceptance for interviews. Furthermore, the pupils were asked by teachers for their acceptance of participation in the interviews. School applications to Danish Veterinary and Food Administration (part of the Ministry) and all other relevant materials (e.g. home pages, policies) have been used as background information.

The data generated in the case studies can be seen in Table 1.

The findings present the participants' perspectives on the school meal projects and their organization, identifying similarities and differences between informants and schools. These presentations are based on detailed case reports developed for each school in order to receive nuanced views of the experienced practice. These reports also form the basis for analyzing the participants' perspectives on the content and practical and social circumstances of the school meals, as well as perspectives on pupils' concepts, competencies and participation in relation to school meals. This analysis has been developed through an abductive process, that is, by alternating between observations, interviews and reflections from the specific cases and broader conceptual and theoretical sources of inspiration, as outlined below (Coffey \& Atkinson, 1996). In the analysis we focus on describing the typical, the most meaningful, as well as the confronting and contrasting issues and variations between informants and schools.

\section{Key concepts and theoretical basis}

The study is inspired by research on school meals as learning arena for children's concepts of foods and meals, and research on children's competences and participation.

Table 1

Data collection, observation studies and interviews.

\begin{tabular}{|c|c|c|c|c|c|}
\hline Surveys & School B & School F & School D & School C & Total \\
\hline Observation studies & 2 days -2 classes $2 \times 3$ hours & 2 days -2 classes $2 \times 3$ hours & 2 days -2 classes $2 \times 3$ hours & 2 days -2 classes $2 \times 3$ hours & 16 \\
\hline \multirow[t]{2}{*}{ Interviews, single - pupils } & 2 pupils grade 6 & 2 pupils grade 6 & 2 pupils grade 5 & 2 pupils grade 6 & \multirow[t]{2}{*}{16} \\
\hline & 2 pupils grade 9 & 2 pupils grade 9 & 2 pupils grade 8 & 2 pupils grade 9 & \\
\hline \multirow[t]{2}{*}{ Interviews, focus - pupils } & 6 pupils grade 6 & 6 pupils grade 6 & 6 pupils grade 5 & 6 pupils grade 6 & \multirow[t]{2}{*}{8} \\
\hline & 7 pupils grade 9 & 6 pupils grade 9 & 6 pupils grade 8 & 6 pupils grade 9 & \\
\hline \multirow[t]{2}{*}{ Interviews class teachers } & 1 teacher grade 6 & 1 teacher grade 6 & 1 teacher grade 5 & 1 teacher grade 6 & \multirow[t]{2}{*}{8} \\
\hline & 1 teacher grade 9 & 1 teacher grade 9 & 1 teacher grade 8 & 1 teacher grade 9 & \\
\hline \multirow{2}{*}{$\begin{array}{l}\text { Interviews, headmaster/school } \\
\text { meal responsible }\end{array}$} & 1 headmaster & 1 school meal responsible (no & 1 headmaster & \multirow[t]{2}{*}{1 headmaster } & \multirow[t]{2}{*}{6} \\
\hline & 1 school meal responsible & headmaster, teachers lead ) & 1 school meal responsible & & \\
\hline
\end{tabular}




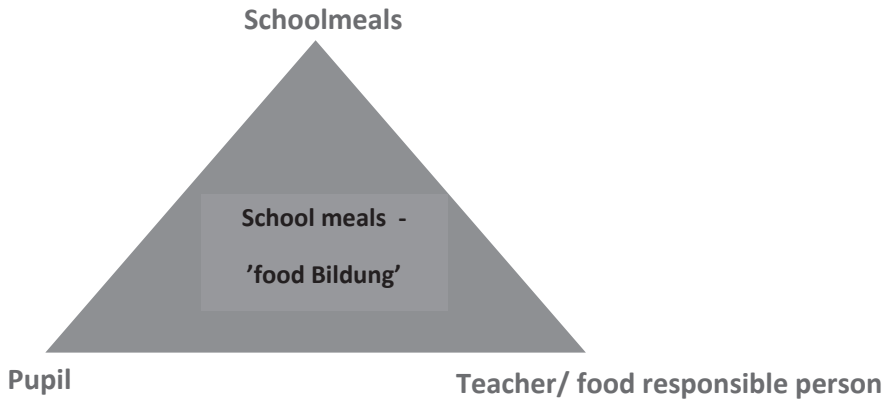

Fig. 1. The didactic triangle elaborated (Benn, 2012).

\section{School meals as a learning arena: Context, content and commensality}

School meals are part of the school day, whether they are free, available to buy or brought from home. Lunch break is an event every day, all year, every year; 'a lesson for life', as it is the most frequent lesson of all in the life in school (Finnish School Board). It can furthermore be viewed as situated learning in communities of practice (Lave \& Wenger, 1999; Wenger, 1999). The potential of school meals as learning lessons is illustrated in Fig. 1, emphasizing the importance of the relationship between the pupil, the teacher/ person responsible for the food and the content of school meals in forming the learning arena for school meals as food 'Bildung'. This institutional relationship can be understood in terms of 'foodscapes', defined as: "the places and contexts where children eat and come into contact with food and the meanings and associations connected to them" (Johansson et al., 2009, p. 30).

The context for and content of the meal are dependent on legislation, policy, pedagogy, and social and concrete circumstances in the school setting. The relationship between the pupil and the meal is embedded in the everyday life of the school: It might just be an occasion for relaxation and informal learning of food, but it can also be a more organized and structured aspect of the school day, part of formal learning of food depending on school policy and pedagogy. The overall aim in school is education, or rather the broader concept of 'Bildung', as used in both the Scandinavian and German languages meaning being educated for self-decision, co-decision and solidarity, ${ }^{1}$ or as Gert Biesta puts it Bildung "is more than simply getting things 'right' but has also do with nurturing the human person, that is has to do with individuality, subjectivity, in short, with 'becoming and being somebody.' " (Biesta, 2006). When it comes to food in school, the aim therefore has to be food 'Bildung' or food literacy. The didactic triangle shows how content is related to pupils and teachers and other relevant persons and this with a learning potential.

The role of the teacher and the character of his/her interaction with the pupil and the school meal influence the learning outcomes and experiences concerning the meal. Persson Osowski talks in her study of "the sociable teacher role, the educating teacher role and the evasive teacher role" (Persson Osowski et al., 2012, p. 41). The sociable teacher has a high level of interaction with pupils; the educating teacher strives to educate pupils in general and about food and nutrition, whereas the evasive teacher has a low level of interaction. But pupils can also be more or less active when participating in the meal situation and choosing or rejecting the food offered.

\footnotetext{
${ }^{1}$ For further study see W. Klafki (2010): The Significance of Classical theories of Bildung for a Contemporary Concept of Allgemeinbildung. In: Westbury, Hopmann, Riquarts, eds.: Teaching as A Reflective Practice: The German Didaktik Tradition. Lawrence Erlbaum Ass., New Jersey: 85-108.
}

Foods and meals are a very personal matter, as the food you put in your mouth cannot be eaten by anyone else, but in the school context and setting the meal can be a collective act and an opportunity for sharing, commensality, and learning. Commensality can be defined "as a gathering aimed to accomplish in a collective way some material tasks and symbolic obligations linked to the satisfaction of a biological individual need" (Grignon, 2001, p. 24), or more direct "commensality is the concept used to describe eating with others" (Sobal \& Nelson, 2003, p. 181). This eating together with others gives rise to learning of foods and meals. According to Birkemo (2002), a good learning environment is a setting where the pupils experience how to:

- belong/be related.

- be an active contributor.

- participate in communication.

- explore.

Wenger states that, in communities of practice, individuals learn to belong, to do, to become and to experience (1999). To belong has to do with the social part of learning and being together, sharing meals in lunch breaks. Active contribution depends on the person being active, but also the opportunity to do so; therefore this is closely related to participation. To explore and experience the meal is what happens during lunch break. Simmel wrote 100 years ago that the meal was the most common human act (Simmel, 1998). The format of a common meal is part of a cultural and social lesson often used to present the next generation to what Murcott calls 'a proper meal' (Murcott, 1986). A proper meal has different meanings depending on who defines the 'properness'. In the case of school meals, the word proper might mean healthy and nutritious as defined by teachers or health professionals, whereas for the children it could also mean that the menu has the right cultural format of foods combined in dishes which can constitute a meal (Douglas, 1975). Through presentations, preferences and experiences, a meal can become what Kurt Lewin called 'food for me'; the food the particular individual is willing to eat (Lewin, 1951). Food preferences differ from one person to another, as well as from one setting and one time to another. "Taste is culturally formed and socially controlled", according to Levi-Strauss (Lévi-Strauss, 1992). The multi-faceted nature of food means individuals continuously face choices that, according to Warde, imply multiple dichotomies such as:

- Freedom versus control

- Power versus discipline

- Economy versus ecology

- Novelty versus tradition

- Pleasure versus health

- Care versus convenience (Warde, 1997).

In school meal based interventions aiming to promote healthy food choices and learning, the pupils, teachers, school health professionals and school management have to face these dichotomies.

\section{Concepts of food and competencies}

Food consists of visible foodstuffs which can be combined into dishes and meals. The concrete foodstuffs and meals eaten contain nutrients, the amount of which depends on the chosen foods, and the quality and quantity eaten. It is foodstuffs and meals which are the visible elements for the children, in this case the school lunch. Over time, the combination of meals consumed forms an individual dietary pattern. These concepts are illustrated in a model of the levels of food: see Fig. 2. 


\section{What is food?}

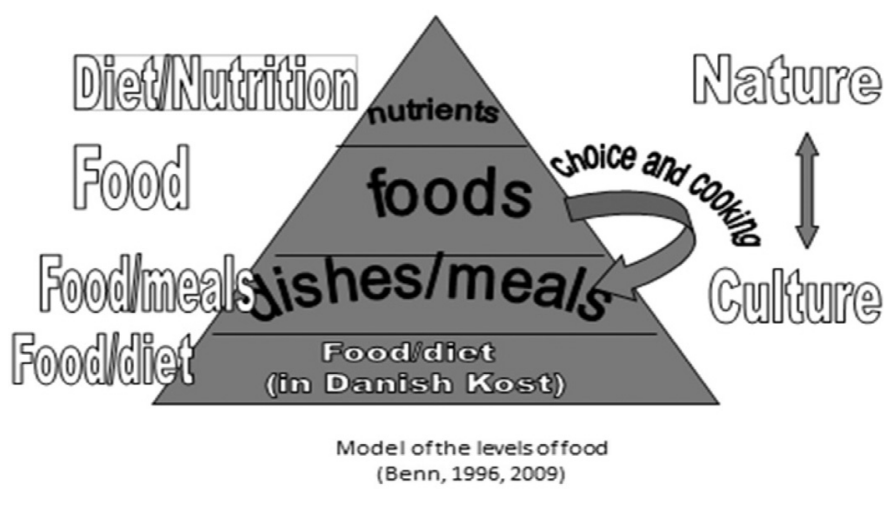

Fig. 2. The elements of food.

The figure illustrates the many different aspects related to food and also how complex it is to talk about food if we are not aware of what the conversation is about. Is it about nutrition and physiology, or about foodstuffs, food choices, composition, taste and cooking? Is it about meals and menus, culture and tradition, or dietary patterns? The figure has been used, alongside the other theoretical approaches, as a tool in understanding how the school meal is described and understood, and to differentiate the aspects and conditions that pupils relate to food. Another way of looking at it is that nutrition is related to digestion, foods to consumption and cooking, and meals to eating, while diet concerns longer term eating habits, revealing lifestyle and living conditions.

Research on pupils' competencies in relation to food, meals and health emphasizes that there exists both a pragmatic, practical dimension, which has something to do with practical skills, and a more theoretical dimension, e.g. knowledge about nutrition and hygiene. In addition, learning about food and health has aesthetic, social, cultural and ethical dimensions. The competence model below, inspired by Delors' operationalization of learning (Delors, 2005), outlines four elements of learning related to food, meals and eating: to know, to do, to be willing, and to be.

The food-related competencies illustrated in Table 1 have a content/knowledge dimension concerning nutrition, food composition and meals. Furthermore, practical skills are needed to produce foods and meals. Besides these elements, there should also be a willingness to participate in general and be involved in decisions concerning food. Finally, the ability to take care of oneself and others is very closely related to foods and meals.

This competence model is aligned with Lave and Wenger's concept of legitimate peripheral participation, where crucial components of learning include: learning as belonging to a community, learning as doing in practice, learning as experience which provides meaning, and learning as becoming and building identity (Benn, 2006, 2009; Wenger, 1999, p. 5). Participation and involvement are, or should be, elements of any education with the objective of empowering learners.
All these dimensions can be present in relation to school meals and as part of formal or informal education and learning. They can each contribute to learning about food, health and meals, and assist pupils in acquiring competencies regarding these issues. Linking the theoretical and practical knowledge about food and health to everyday life competencies can be valuable. The analysis will focus on these issues, and the theoretical approaches concerning content, context, competencies and participation will contribute to the discussion of the empirical study.

\section{Results and discussion}

Pupils' and teachers' perspectives on the school meal projects and its potentials for learning

As shown in Table 2 below, there are many similarities between the four schools concerning the organization of school meals and the pupils' and teachers' involvement in the school meal projects: The intervention projects did not include planned educational components, and the teachers mainly took part in the school meal projects by eating with the pupils (mainly in the grades up to 7 and sometimes with grades 8-9). At all four schools, lunch was consumed in commensality in the classroom. The pupils were mainly involved as food assistants, which meant they fetched food for the class. The school meals offered in the intervention period were mainly cold, portion-packed meals such as sandwiches and salads, and in that regard quite similar to the packed lunches the pupils usually bring to school. An exception was the Rudolf Steiner School (Waldorf School) (school F) which also provided hot meals, both during and outside of the intervention period.

Schools B and D are large schools with many pupils and teachers (750-780 pupils), whereas $\mathrm{F}$ and $\mathrm{C}$ are smaller schools (250340 pupils). The initiative to participate in the free school meals intervention project came from the headmasters in schools $\mathrm{C}$ and $\mathrm{D}$, while it was the school and parent boards that took the initiative in schools B and F.

Short case summaries of pupils', teachers' and headmasters' perspectives on school meals and the organization of the school meal project are presented below, followed by a short discussion.

\section{School B}

The pupils were positive regarding the communal meal, even though the compulsory participation meant a reduction in the oldest pupils' opportunities to leave the grounds. Nevertheless, the pupils would have preferred more options. They did not see a learning potential in the project, but could see a possibility to learn about food and health if they had been more involved in the school meal project.

Teachers considered school meals as an essential part of the school day, but did not find learning opportunities in the project. Furthermore, they found the food of varying quality, both nutritional and culinary, and, due to the standardized portion sizes, not always sufficient in quantity. They would have liked to have been involved in the project during the planning.

The headmaster and the person responsible for the food were not satisfied as the frequently poor food quality resulted in consid-

Table 2

Dimensions and elements of food-related competencies (Benn, 2006, elaborated 2013).

\begin{tabular}{|c|c|c|c|}
\hline Competencies overall & Elements & Dimensions & Examples \\
\hline Knowledge of coherence & To know & Content dimension & $\begin{array}{l}\text { Knowledge of coherences between what you do and consequences e.g. } \\
\text { intake of food and drink }\end{array}$ \\
\hline Everyday life competence & To do & Acting dimension & Be able to master everyday life practically and pragmatically \\
\hline Citizenship and participation & To be willing & Participatory dimension & Be willing to participate in the everyday life in school and class \\
\hline Carefulness, to be empathic & To be and become & $\begin{array}{l}\text { Cooperative, social and } \\
\text { subjective dimension }\end{array}$ & Be caring in the life world you are part of, for yourself and for others \\
\hline
\end{tabular}


erable waste. They could, however, see possibilities for learning if the school meal project was redesigned.

\section{School F}

At this private Rudolf Steiner School, the board of governors decided to offer a vegetarian lunch. The pupils highlighted both positive and negative aspects. They could help themselves to food from big bowls, but sometimes there was not enough for those with a bigger appetite. They, generally, enjoyed eating together in the classroom, although it meant that the oldest pupils could no longer leave the grounds during the lunch break.

The teachers (who were parents of pupils, sat on the board of governors, and also functioned as head teachers) have seen the project as an opportunity to introduce healthy, delicious vegetarian food to the pupils, so that they would learn more about ecology, food and diet. They found that the supplier was not able to provide proper vegetarian food, and that the learning potential of the school meal therefore was not fulfilled.

\section{School D}

The student council was involved in tasting examples of school meals before the project's launch. They found that the actual meals provided were of a lower quality, but they were positive regarding the potential for communal school meals strengthening the pupils' concentration and the social environment in the class.

The teachers took a generally positive view of the idea of universal free school meals, but they disagreed on whether it is a task for the school, which should be incorporated in education and learning, or just part of school health policy. The teacher responsible for school meals was unsure whether the responsibility should be taken away from parents.

The headmaster finds the school meals valuable but considers them the responsibility of parents. The link between school meals and education is not seen as obvious, and school meals are found too time consuming at the expense of necessary 'formal education' tasks.

\section{School C}

The pupils, especially those in grade 8, were not satisfied with the quality and quantity of the meal, but saw it as a possibility to get lunch and more varied food. They are unsure of the healthiness of the meal and would like the opportunity to choose and have their say concerning the meals. Some would also like to be involved in cooking the meals.

Teachers see a positive effect in relation to the pupils who do not usually bring lunch boxes. Like the pupils, however, they are not satisfied with the quality of the food. They would like to involve pupils in projects concerning food, and relate school meals to education, especially to the subject home economics.

The headmaster sees parents as having the primary responsibility for the pupils' health, but would like to establish a permanent arrangement if more than one-third of parents want this. He points out that this should be done in cooperation with teachers, the student council and the school board, and also sees a possibility for involving pupils in a future school meal project.

\section{Summary}

Pupils, teachers and headmasters at all four schools pointed out the need for greater involvement of the pupils and found that the free school meals were somewhat lacking in quality. The pupils at all four schools wanted to have wider options than the meals provided. They particularly emphasized the positive experience of eating together in the class, including an improvement of the social environment. The teachers and headmasters at all fours schools placed particular emphasis on the low nutritional and culinary quality of the meals. Besides that they are concerned about economic and eco- logical sustainability if school meal projects are going to be continued as a lot of waste on food was experienced.

The teachers and headmasters see a learning potential in school meals if pupils and teachers are offered a more central role. While the teachers are generally positive regarding a universal free school meal, they are unsure whether it should be a school task. Most teachers see school meals less as part of education and learning, and more as part of school health policy and practice. However, the teachers are more inclined than the headmasters to see the educational potential of a communal school meal, especially in relation to the subject home economics. The headmasters stress that the responsibility for meals should primarily stay with the parents: One of the concerns is that it takes time from the necessary educational tasks of the school, and another concern is the organizational demands of distributing meals and removing waste.

\section{The content of the school meals - learning, tasting, eating}

School lunches are provided in all cases by an outside catering company, and the schools have little say in terms of content. A clear policy for the lunches was only developed at school D. At school F, a vegetarian concept was chosen, but financial constraints meant that the use of organic and biodynamic ingredients, at the heart of Steiner's philosophy, had to be abandoned. This illustrates the dichotomy between economy and ecology, pointed out by Warde (1997).

At School B, the headmaster had the following vision:

"Of course they have to deliver a healthy and good meal which can last the pupils the whole school day. It also has to be quite exciting both to look at and to taste. And then is has to be designed for children, which means you have to avoid mixing too many ingredients together that they will sit and pick apart . . . if they do not like the food, they do not eat it."

This could be clearly observed when fish burgers were on the menu. Not many pupils ate them resulting in a mountain of untouched or half eaten burgers. Acceptance and rejection are part and parcel of late-modern consumer life, and food is no exception. During the project, the schools did try to change the menus in line with pupils' preferences so as to reduce waste. But they cannot avoid the dichotomy between freedom and control (Warde, 1997), the freedom to take or reject. This can also be seen as dealing with the institutionalization of the meal; i.e., one size fits all with no individual choice.

"In general it tastes good, but there is something with it, something about it, so you do not want to eat it; then I ate half of it, and then I thought I am not hungry any more, I cannot eat this in this way. There is something about it: it tasted good, but it is unappetizing." (Girl grade 8, B).

At first the girl is willing and wants to eat, to participate in the meal, but she expresses another aspect concerning institutional meals: 'it is not my private meal'; 'there is something about it'. It is not 'food for me', to put it into Lewin's terms.

The interview excerpt below illustrates the dichotomy between taste or pleasure and health, as well as underlining the pupils' expectations that a proper school meal needs to offer both (focus group, grade $9, \mathrm{~F})$ :

Girl: "I really think that there should be more focus on what is healthy."

Boy: "Yes, yes, but it still has to taste good."

Girl: "Yes, but it can taste good as well."

Boy: "Yes, it can . . . but l'd say, of course it has to be healthy, but I still want to put taste in first place for school meals." 
The school meals also contain the dichotomy raised by Warde concerning novelty and tradition: an institutional meal has certain inherent problems in satisfying the preferences of different individuals, but also advantages in terms of openness to new or unfamiliar food which some of the pupils would not normally eat. A female teacher at school B explains:

"I think there also are some who have tasted something they might not normally have in their lunch box. And I think that some would think, oh that is a good idea, and this could be something I made myself and brought in my lunch box. And sometimes they have been surprised: No, I did not think I would like this at all."

According to the teacher, the pupils have been exploring different foods which can be seen as a fundamental part of a potential learning outcome from school meals.

The pupils generally take the view that the school meals should be both healthy and tasty. However, most pupils found the meals on the offer less than healthy, and a boy, grade 8 (C) said: "It is not what they (the catering company) promised before the delivery." A problem in three of the schools was that the portions were the same, whether for a fully grown boy in grade 9 or a little girl in grade 3, and side dishes such as bread were not always provided. In general, the pupils focus on their understanding of quality food, as food that satisfies their appetite, tastes good, is healthy and varied. They would also like to be offered a choice. In other words these perspectives are related to the dichotomy between freedom and control concerning food choices, emphasized by Warde (1997).

“. . . if there were some more things to choose between, e.g. if you do not like chicken curry, if there was then another dish to choose" (girl 9th grade, F).

"It does not mean that there has to be a lot to choose between, just 2-3 different dishes, and perhaps more meat and hot food. There is way too much pasta, anyway." (Boy 8th grade, C).

"It would be better if you could choose the food yourself" (Boy 5 th grade, $\mathrm{C}$ ).

As pointed out in the summary of headmasters' and teachers' perspectives on whether school meals are a task for the school or solely the parents' responsibility, headmasters generally agree that parents should maintain primary responsibility, but some are concerned about parents not living up to this responsibility. The headmaster at school C emphasizes: "today we talk just as much about well-being as about teaching. The basic idea is that you cannot teach children who are not feeling well", and elaborates:

“I consider it the parents' responsibility . . . that the children get proper nutrition. But in the real world, ... . we find many children who do not function well because they do not get proper food. It should not be like that, but it is, so the school has to offer school meals."

The headmaster at school B, meanwhile, found: "I'm afraid that we in some cases have got poorer school meals, which have replaced the good lunch boxes brought from home."

The dilemma of school meals and the school's responsibility to ensure pupils receive the necessary nutrition is evident: At $C$, the headmaster finds it necessary that the school assumes this responsibility, whereas the headmaster at B finds that the nutritional value of the institutionalized school meal is insufficient, and that packed lunches from home generally provided a better alternative.

To summarize, the participants' perspectives on the content of the school meals illustrate how their visions of what constitutes a good school meal (organic, nutritious, healthy, and tasty) were compromised by financial constraints and by a lack of competence among the catering companies. The institutionalization of school lunches also resulted in issues such as pupils with no other choices on offer, not finding the day's lunch palatable and therefore refusing it, leading to considerable waste. Perhaps the most obvious potential for learning is to be found in the situations where pupils discuss whether food can be both tasty and healthy, and in one teacher's highlighting of the opportunities for tasting something new and incorporating it in future lunch box habits. However, the perspectives uncovered in the analysis, pointing at dichotomies between economy versus quality, and between freedom and control (to take or reject according to what you consider an acceptable 'food for me'), could also hold a considerable learning potential if discussed with the pupils. It would imply that the foods and meals are seen in schools and by teachers as a possible and essential learning area, where both foods, meals, and nutrients as seen in Fig. 2 are set at the agenda dealt with sometimes at the meal and in other cases in the relevant school subjects.

\section{Practical and social learning circumstances of the school meals}

As shown in Table 2, pupils at all four schools usually eat lunch together in the classroom, although the schools' rules allowed pupils from grades 8-9 to leave the school in the lunch break, where they often buy food and eat in smaller groups. During the project period all pupils had to stay inside for 10-20 minutes during the lunch break. For many of the older pupils this was annoying at first, but after a while the social benefits of the meal situation seem to have increased enthusiasm for the school meal project among the majority: The older pupils realized that they actually enjoyed eating together in the classroom. The interview excerpt below stresses the good atmosphere, the sense of community, and the absence of noise.

"In fact I think it is really good this way that we must eat in the class room . . . I find it really cozy that we can sit and talk and all that, and you are together with your classmates - without a lot of other people and noise and stuff." (Girl 8th grade, C).

A teacher at the same school, on the other hand, says: "I think they should have a separate room to eat in, a canteen, where different year groups eat together and eat some food they have chosen themselves on a plate with a knife and fork." This mirrors her view of a proper school meal, which involves free choice, eating in a special room, and dining artefacts. Some of the older pupils would also like to have a canteen and envisage a cozily decorated space, free of surveillance. The taste of the food is, as seen from the following interview excerpt, important for creating a pleasurable meal experience. "If it is a day when all of us like it (. . .). Then it is cozy that everyone is sitting in their places and eating the same food, and you sit and talk about how good it tastes." (Boy, grade 8, B)

In grade 5, especially some of the boys thought that the project's rule about having to stay in the classroom for 10-20 minutes even if they had finished their meal was annoying because "it is far too much time to just eat," and then "we cannot get the best football pitches." This illustrates the dilemma of the school lunch break: should it be free time for the pupils, or part of schooling and learning, whether formal or informal (see, e.g. Persson Osowski, 2012).

The organization of the meals varies, mainly dependent on the teachers, and is stricter in the lower grades where pupils have to remain seated, are not allowed to swop parts of lunches, and are expected to be quiet and just eat. The older pupils are allowed to move around the classroom, talk and socialize during the meal. Besides these socializing or disciplining aspects of the educating teacher role (Persson Osowski, 2012), observations also indicated that some teachers had a high level of interaction with pupils during the meals. They strived to engage the pupils in discussions about 
the nutritional content of the food, and to create a nice atmosphere, and a sense of sharing a meal. Other teachers had a low level of interaction and either did not eat with the pupils, or, if required to do so (as in the lower grades), limited their interaction to the maintenance of peace and order. This could be seen as an example of a more evasive teacher role.

Three central aspects concerning the practical and social circumstances of the school meals are emphasized by the pupils and teachers above:

- place and atmosphere.

- rules and rituals related to time and place to eat.

- the role of the teacher related to the qualification and socialization aspects of the meal.

This indicates that the learning arena in school meals is created both in the pupils' interaction with the practical and social circumstances of the school meal itself and in the teachers' interaction with the pupils and the school meal. This finding is in accordance with Fig. 1, which emphasizes the importance of the relations between pupil, teacher and school meals, and with the concept of foodscapes, highlighting places, contexts and meanings connected to meals.

\section{Learning, concepts, competencies and participation in school meals}

In the study, certain multi-faceted aspects emerge concerning the pupils' knowledge of concepts and understanding of foods and meals. If one considers the food layers in Fig. 2, foodstuffs could be recognized and their origins could be discussed, taste schemes could be supplemented to learn how to discriminate different tastes and how to eat a more varied diet. Meals could also be analyzed in terms of nutrients and could be related to pupils' understanding of these.

"There is something new I have not tried before, also something you know but then it is combined in a new way ... But especially that you try something new." (Girl grade 5, B).

Many of the teachers underline the benefits of pupils trying new ingredients and dishes - exemplified above in the section on the content of the school meal. As one of the teachers at the Rudolf Steiner School envisions below, pupils could also learn from experience with producing food for school meals.

"We would like them to experience foods themselves ... That they know that the carrot is pulled out of the ground . . . and all the respect there should be for the work and the proper nutrition." (Teacher, F).

The excerpts from pupil interviews below indicate that they have a good general understanding of nutrition and health, expressed as avoiding fatty food items, junk food, and eating too much, but also knowing how to ensure a balanced diet. All part of the competence 'to know' (Table 1) and also to some degree has knowledge of coherences.

“Are pizza slices, like you were given today, healthy?" (Interviewer).

"No, and you should not eat too many, but if you had got some salad to go with it and an apple, it would be healthier." (Girl grade $6, F)$.

"I think you must eat the proper amounts, and at the right times, and then no sugar and all that. But some good stuff." (Girl grade 9, F).

"We have learnt to eat healthy so the body gets all the vitamins and everything we need." (Girl grade 5, B).
The pupils here express some understanding and knowledge of the different levels of food that can be seen in Fig. 2. They talk of food as necessary for their health, i.e. nutrition (level 1) both concerning variety and amounts of nutrients, but they also consider taste and meal experiences (levels 2 and 3). Teachers and pupils do not generally see school meals as a tool to learn about foodstuffs or nutrients and diets, or any other element of learning that is described in the competence model in Table 2. However, the passages above show that something has been learnt, mainly focusing on the knowledge element - 'to know' - and illustrating the many different types of knowledge which can be related to food: from nutrition to healthy eating habits.

'To do' deals with more practical issues, such as choosing, combining and cooking food, which have not been on the agenda during the school meals intervention. Two of the teachers point out the missed learning opportunities in omitting this element:

"I would prefer if pupils were involved in cooking, the older pupils, and we have that possibility (a school canteen and kitchen); someone has to be responsible of course. And the classes could learn something. Make a project with a theme. I think they would have a greater sense of ownership in relation to the meals." (Teacher, School B).

"I read about a school which did it (involved pupils in preparing and serving the meal). They had a person employed with knowledge in this area - cooking with children - and classes took turns. Yes it would be good, because I think they need to have hands on; to have the food in their hands in order to give them an attitude towards this so they can form their own meaning." (Teacher responsible for school meals, School D).

"To be willing" to participate, to acquire and show social competences have already been discussed in the section on the social circumstances of the school meals where the pupils refer to positive experiences with eating together. The following passages reaffirm the importance of the social aspects of the dining experience for both teachers and pupils:

"I think we should indeed look at well-being from a health perspective ... For a school of this size, you could imagine that year 8 eats with year 2, 9 with 1 . Yes, that we mix the classes up . . . it is a happy feeling to eat together." (Teacher, School B).

"Someone from my class suggested yesterday that, in the class, you could sign up to make lunch for one another. . ., and the older kids could cook for the younger ones." (Girl, grade 5, C).

The last interview part shows both willingness to participate and to care for others (Table 1 ).

However, pupils and teachers had little involvement in decisions concerning the school meal project. It was a top-down decision which, as one teacher puts it, "can be seen as failing to offer a sense of project ownership and lacking perspectives and inputs from the very people who make up the target group." At school B the pupils were asked to use smileys to assess the meals, thereby placing the pupils in the role as consumers, although it is not clear if their assessments had any bearing on the choice of meals in the school project. If this is to have an educational purpose, the tasting and testing of meals has to both engage pupils in a discussion about their judgments and understanding of food, meals and nutrition, and (with reference to Lave \& Wenger, 1999) to involve them in legitimate peripheral participation regarding the possibilities of influencing decisions on school meals.

In some cases pupils were consulted before the project concerning the specific catering options, and were involved in tasting and testing at two of the schools. At school B representatives from the student council were invited to an introductory seminar concerning the project Here, they were nominated as governors for the meal 
Table 3

Characteristics - selected items.

\begin{tabular}{|c|c|c|c|c|}
\hline Characteristics & School B & School Fa & School D & School C \\
\hline $\begin{array}{l}\text { Relation to planned } \\
\text { educational components }\end{array}$ & $\begin{array}{l}\text { None - besides making smileys } \\
\text { for the meal }\end{array}$ & None & None & $\begin{array}{l}\text { None - besides a health week } \\
\text { as introduction }\end{array}$ \\
\hline Teachers' main involvement & $\begin{array}{l}\text { Eat with children grades up } 7 \text {, } \\
\text { sometimes with grades } 8-9\end{array}$ & $\begin{array}{l}\text { Eat with children grades up } 7 \text {, } \\
\text { sometimes with grades } 8-9\end{array}$ & $\begin{array}{l}\text { Eat with children grades up } 7 \text {, } \\
\text { sometimes with grades } 8-9\end{array}$ & $\begin{array}{l}\text { Eat with children grades up } 7 \text {, } \\
\text { sometimes with grades } 8-9\end{array}$ \\
\hline Pupils' main involvement & Food assistants & Food assistants & Food assistants & Food assistants \\
\hline Meals in general & $\begin{array}{l}\text { Mainly cold dishes, portioned, } \\
\text { packed to eat directly }\end{array}$ & $\begin{array}{l}\text { Vegetarian offer, hot and cold } \\
\text { dishes served from common } \\
\text { bowls }\end{array}$ & Cold dishes, portioned & $\begin{array}{l}\text { Cold dishes, portioned, packed } \\
\text { to eat directly }\end{array}$ \\
\hline Meals at the visit & $\begin{array}{l}\text { 1. Pasta salad and bread } \\
\text { 2. Fish burger }\end{array}$ & $\begin{array}{l}\text { 1. Curry stew and rice } \\
\text { 2. Cream potatoes, rice cookies } \\
\text { and apples }\end{array}$ & Sandwiches and salad & $\begin{array}{l}\text { Rye bread bun with ham, } \\
\text { cheese and } 1 \text { carrot }\end{array}$ \\
\hline
\end{tabular}

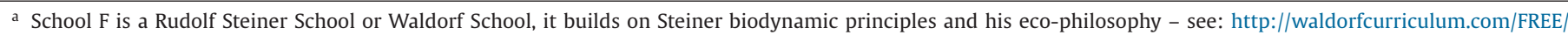
THE\%20EDUCATION\%20of\%20the\%20child.pdf.

project, which might be seen as education for citizenship and democracy. But they were not involved once the project was launched. This can be seen as an example of (the promise of) participation being used as a motivation strategy in health promoting interventions; a strategy commonly identified in other studies of school based health promotion (see, e.g. Simovska \& Carlsson, 2012). Not being taken seriously detracts from the pupils' experience of participation, and has a negative impact on the possibility of promoting a participatory competence dimension in relation to school meals (see the competence model Table 3). Pupils' participation needs to be taken seriously if they, as Wenger puts it, are going to have a chance of learning to belong (to a community of practice), and to become a participant in this community (Benn et al., 2010; Wenger, 1999).

\section{Conclusion and perspectives}

Serving free school meals did have learning potentials for the pupils. The meal and foods offered a possibility to learn, to taste new foods and dishes, and the common meal gave further rise for another social learning more than the traditional breaks dependent on own foods brought from home or bought outside, as all pupils were eating the same meal, they were sharing a meal. The interviews showed learning potential in informal learning arenas, as the pupils were able to communicate and reflect on the offered school meals.

Lunch is an event in the school day, whether it is a communal, formalized meal, as in the school meal projects explored in this study, an organized activity with learning objectives, or just a break where pupils each consume their own personal packed lunch. This study concludes that school meals can contribute to learning, whether planned or not. However, if the school meal is to be further developed as an arena for learning, greater consideration must be given to the interaction between the pupil, the school meal and the teacher than what has been the case in the projects presented here. Clarification and discussion of the learning objectives and the educational idea of school meals as a learning arena for food 'Bildung' is also required.

The study of the school meal projects raises the following questions and dilemmas:

- Should the lunch break be free time for the pupils - or a timetabled educational activity?

- Should school meals be 'food for learning' - or primarily enjoyable events for the school community?

- Should school meals be based on participation and shared responsibility among pupils and teachers - or just a catering option?

- Is food in schools a common, public responsibility - or the private responsibility of the families?
It can be discussed whether the school lunch break needs to be a complete break from educational activities, from pedagogy and grown-ups: a break where the pupils themselves can decide how to spend their time. It may also be discussed whether school meals are the society's responsibility and a part of the school curriculum or if they are the sole responsibility of pupils and their parents. In any case, the school meal is part of every school day and thereby 'a lesson for life'.

The possibility of further developing school meals as a learning arena depends on which meanings and understandings are connected to school meals, and the way foods and meals is dealt with in the schools; in other words on both the cultural, the practical and the social circumstances surrounding the school meal. If the purpose is formal education of topics such as nutrition, food, cooking and meals, there has to be a curriculum describing this. But this study showed clearly that getting a free meal, eating it together do hold informal learning potential; however, both formal and informal learning could and should have been considered more clearly in all four schools. Furthermore the conditions of the project concerning a correspondence between the school meal offer and education and learning should have been more clearly outspoken in the application form. As this and other studies exploring health promotion interventions in schools have pointed out (see, e.g. Clarke, O'Sullivan, \& Barry, 2010; Carlsson \& Simovska, 2012), the interplay between project implementation and contextual factors (including educational values and practices) substantially influences learning opportunities. There are implications of election of these specific four schools. School C was placed on a small island and had to use the local food provider, whereas the other schools could choose among different providers. Another implication of election is the Rudolf Steiner School (F) with its special philosophy and approach to food. But on the other hand they are also two of many schools with those characteristics. School B and D are similar and represent typical Danish schools in all regions.

In relation to the participants' perspectives on the content of the school meals, the dichotomies of foods and meals proposed by Warde - economy versus quality; freedom versus control; pleasure versus health; and novelty versus tradition - seem to hold considerable educational potential. The perspectives and visions related to the learning potential of school meals presented in the analysis above underline that an optimal organization of learning through school meals would include: opportunities for pupils to develop practical action competence dimensions, opportunities to explore and develop social competence dimensions, as well as learning opportunities encouraging active participation in the everyday life of the school in relation to school meals. In other words, it needs not only to encompass to know, but also to do, to be willing and to become (Benn, 2009). As Weaver-Hightower argues, "we can and should instead view food as an integral component of the ecology of education - the broader 
interconnections, actors, relationships, conditions, and processes of which education is composed" (Weaver-Hightover, 2011, p. 16). The implications for this is that we take food seriously and the school arena as part of pupils' food education or 'Bildung'.

\section{References}

Benn, J. (1996). Kost i skolen. Skolekost I, en undersøgelse af forhold, tilbud og muligheder i forbindelse med skolernes spisepause. Fra fattige børns bespisning til sundhedspædagogiske projekter. København, Danmarks Lærerhøjskole (Food in schools. School meals, a survey of conditions, offers and possibilities regarding the lunchbreaks in schools).

Benn, J. (2006). Hjemkundskab, dannelse og kompetence (Home Economics, 'Bildung' and competence). Cursive, 1, 99-118.

Benn, J. (2009). Mad, kost, ernæring - er det et fedt. Børn og unges forståelser og erfaringer på madområdet [Food, diet, nutrition. Is it all the same]. In M. Carlsson, V. Simovska, \& B. B. Jensen (Eds.), Sundhedspædagogik og sundhedsfremme. Teori, forskning og praksis [Health education and health promotion. Theory, research and practice] (pp. 193-210). Aarhus: Aarhus Universitetsforlag.

Benn, J. (2012). Omsorg i profession og hverdagsliv. In V. Simovska, \& J. M. Jensen (Eds.), Sundhedspædagogik i sundhedsfremme. [Care in profession and everyday life] (pp. 125-140). København: Gads Forlag.

Benn, J., Carlsson, M., Hesselvig Mortensen, L., \& Lindegaard Nordin, L. (2010). Giver skolemad næring for læring. Læringsmiljø, trivsel og kompetence. EVIUS, delprojektrapport 3 (Do school meals offer opportunities for learning. Learning environment, wellbeing and competence) (Report). Available from http:// forskningsbasen.deff.dk/Share.external?sp=Sf0a93868-23b0-4d90-9704$3 \mathrm{fff} 5839178 \mathrm{e} \& \mathrm{sp}=$ Sau.

Biesta, G. (2006). Beyond learning. Democratic education for a human future. Boulder: Paradigm Publishers.

Birkemo, A. (2002). Læringsmiljø og utvikling. Oslo. Unipub skriftserier, Universitet i Oslo, Pedagogisk forskningsinstitutt (Learning environment and development).

Borgnakke, K. (2004). Etnografiske studier I læring. Mellem klassiske metoder og senmoderne udfordinger. In E. Damberg (Ed.), Et analystisk blik på senmodernitetens grymnasium. [Ethnographic studies in learning. Between classical methods and late-modern challenges]. Gymnasiepædagogik (Vol. 47, pp. 223-258). Gymnasiepædagogik, Roskilde: RUC.

Burgess, R. G., \& Morrison, M. (1998). Ethnographies of eating in an urban primary school. In A. Murcott (Ed.), The nation's diet (pp. 209-227). London, New York: Longman.

Carlsson, M. S., \& Simovska, V. (2012). Exploring learning outcomes of school-based health promotion. A multiple case study. Health Education Research, 27(3), 437-447.

Clarke, A. M., O’Sullivan, M., \& Barry, M. M. (2010). Context matters in programme implementation. Health Education, 110, 273-294.

Coffey, A. J., \& Atkinson, P. A. (1996). Making sense of qualitative data. Complementary research strategies. London: Sage.

Delors, J. (2005). Delors four pillars of learning. Localised 10.09.2013 Available from http://www.unesco.org/delors/fourpil.htm.
Douglas, M. (1975). Deciphering a meal. In M. Douglas (Ed.), Implicit meanings. Essays in anthropology. London: Routledge \& Kegan Paul.

Eisenhart, M. (2001). Educational ethnography past, present, and future. Ideas to think with. Educational Researcher, 30(8), 16-27.

Grignon, C. (2001). Commonsality and social morphology. An essay of typology. In P. Schollier (Ed.), Food, drink, and identity in Europe since the Middle Ages (pp. 23-33). New York: Berg.

Gullberg, E. (2006). Food for future citizens. School meal culture in Sweden. Food, Culture and Society, 9(3), 337-343.

Halkier, B. (2008). Fokusgruppeinterview [Focus Group Interview]. Köbenhavn: Forlaget Samfundslitteratur.

Johansson, B., Mäkelä, J., Roos, G., Hillén, S., Hansen, G. L., Jensen, T. M., et al. (2009). Nordic children's foodscapes. Images and reflections. Food, Culture and Society: An International Journal of Multidisciplinary Research, 12(1), 25-51.

Kvale, S., \& Brinkmann, S. (2008). InterViews. Learning the craft of qualitative research interviewing. London: Sage Publications, Inc.

Lave, J., \& Wenger, E. (1999). Situated learning. Legitimate peripheral participation. Cambridge: Cambridge University Press.

Lévi-Strauss, C. (1992). The raw and the cooked. Introduction to the science of mythology 1. Harmondsworth: Penguin Books.

Lewin, K. (1951). Field theory in social science. New York: Harper \& Row.

Morgan, K., \& Sonnino, R. (2007). Empowering consumers. The creative procurement on school meals in Italy and the UK. International Journal of Consumer Studies, $31,19-25$.

Murcott, A. (1986). Opening the 'black box' Food, eating and household relationships. Socioaaliliaaketieellinen Aikakauslehti, 23(2), 85-92.

Persson Osowski, C. (2012). The Swedish school meal as a public meal. Collective thinking actions and meal patterns. Uppsala: Uppsala Universitet.

Persson Osowski, C., Göranzon, H., \& Fjellström, C. (2012). Children's understanding of food and meals in the foodscape at school. International Journal of Consumer Studies, 36, 54-60.

Pike, J., \& Colquhoun, D. (2009). The relationship between policy and place. The role of school meals in addressing health inequalities. Health Sociology Review, 18, 50-60.

Raulio, S., Roos, E., \& Prättälä, R. (2010). School and workplace meals promote healthy food habits. Public Health Nutrition, 13(6A), 987-992.

Regeringen (2009). Sundhedspakke 2009, København.

Simmel, G. (1998). Hvordan er samfundet muligt? Udvalgte sociologiske skrifter. [How is society possible]. Selected sociological writings. København: Gyldendal.

Simovska, V., \& Carlsson, M. S. (2012). Health-promoting changes with children as agents. Findings from a multiple case study research. Health Education, 112(3), 292-304.

Sobal, J., \& Nelson, M. K. (2003). Commensal eating patterns. A community study. Appetite, 41, 181-190.

Tikkanen, I., \& Urho, U. M. (2009). Free school meals, the plate model and food choices in Finland. British Food Journal, 111(2), 102-119

Warde, A. (1997). Consumption, food and taste. Culinary antinomies and commodity culture. London: Sage Publications.

Weaver-Hightover, M. B. (2011). Why researchers should take school food seriously. Educational Researcher, 40(1), 15-21.

Wenger, E. (1999). Communities of practice. Learning, meaning, and identity. Cambridge: Cambridge University Press. 